\title{
Terapêutica cirúrgica na síndrome de Fournier: relato de caso
}

\author{
Surgical therapy in Fournier syndrome: case report
}

\author{
Daniel Rosa Moreira', André Luis Santana Gonçalves², \\ Renato dos Santos Aucelio ${ }^{3}$, Kamila Gonçalves da Silva ${ }^{4}$
}

Moreira DR, Gonçalves ALS, Aucelio RS, Silva KG. Terapêutica cirúrgica na síndrome de Fournier: relato de caso / Surgical therapy in Fournier syndrome: case report. Rev Med (São Paulo). 2017 abr.-jun.;96(2):116-20.

RESUMO: Síndrome de Fournier ou Gangrena de Fournier é uma fasceíte necrotizante que acomete região perineal, perianal e genital, ocasionada por uma infecção polimicrobiana sinergística de bactérias aeróbicas e anaeróbicas, com predomínio em homens em média aos 50 anos. A enfermidade é caracterizada por uma endarteríte obliterante causando trombose vascular subcutânea e necrose de tecidos. Microrganismos distintos aparecem como patógenos nas culturas dos pacientes com essa enfermidade. $\mathrm{O}$ quadro clínico pode se manifestar com dor, eritema e edema, cianose e crepitação em bolsa escrotal e períneo associada ou não a febre e calafrios. Diagnóstico e intervenção precoce, com antibioticoterapia de largo espectro e drenagem ampla, permitiu melhores resultados nestes doentes. A mortalidade permanece elevada quando o diagnóstico é tardio e o tratamento operatório retardado. O objetivo do artigo é relatar um caso de Síndrome de Fournier em um paciente de 52 anos e discutir a melhor abordagem cirúrgica e seus impactos no sucesso terapêutico nesta enfermidade.

Descritores: Gangrena de Fournier; Faciíte necrosante/cirurgia; Antibacterianos/uso terapêutico; Terapêutica; Relatos de casos.

\begin{abstract}
Fournier syndrome or Fournier's gangrene is a necrotizing fasciitis that affects the perineal, perianal and genital region, caused by a polymicrobial infection of aerobic and anaerobic synergistic bacteria predominantly in men, on average at age 50 . The disease is characterized by obliterative endarteritis causing subcutaneous vascular thrombosis and tissue necrosis. Different microorganisms appear as patogens in cultures of patients with this disease. The clinical picture may manifest as pain, redness and swelling, cianosis and crepitus in the scrotum and perineum with or without fever and chills. Early diagnosis and intervention with broad spectrum antibiotics and ample drainage contributed to a better outcome for these patients. Mortality remains high when diagnosis is late and the surgical procedure postponed. The aim of this paper is to report a case of Fournier syndrome in a 52 year old patient, discuss the best surgical approach and its impact on therapeutic success in this disease.
\end{abstract}

Keywords: Fournier gangrene; Fasciitis, necrotizing/surgery; Anti-bacterial agents/therapeutic use; Therapeutics; Case reports.

1. Médico Residente de Clínica Médica do Hospital de Base DF (HBDF), Brasília, DF. E-mail: daniel.rosa.moreira@gmail.com.

2. Médico residente de Psiquiatria do Hospital das Forças Armadas DF (HFA-DF), Brasília, DF. E-mail: andreluis109@hotmail.com.

3. Médico urologista, Professor de Urologia e Cirurgia Geral do Curso de Medicina da Faculdade Atenas, Paracatu, MG. E-mail: raucelio@hotmail.com.

4. Estudante de Medicina da Faculdade Atenas, Paracatu, MG. E-mail: kg.kamilagoncalves@hotmail.com.

Endereço para correspondência: Daniel Rosa Moreira. Rua MV4 Quadra 6 Lote 14, Morada Verde, Ceres, GO. E-mail: daniel.rosa. moreira@gmail.com. 


\section{INTRODUÇÃO}

síndrome de Fournier ou Gangrena de Fournier é uma fasciíte necrotizante que acomete região perineal, perianal e genital, podendo se estender para a raiz da coxa, parede abdominal e retroperitônio, com predomínio em homens ${ }^{1}$ afetando todas as faixas etárias, em média aos 50 anos $^{2}$.

A fisiopatologia dessa enfermidade é caracterizada por uma endarteríte obliterante causando trombose vascular subcutânea e necrose de tecidos, desencadeada pela ação patogênica sinergística de uma flora polimicrobiana aeróbica e anaeróbica. $\mathrm{O}$ tecido desvitalizado favorece a entrada de bactérias em áreas previamente estéreis ${ }^{3}$.

Entre as doenças que podem predispor à Síndrome de Fournier, o Diabetes Mellitus é encontrado em 40\% a $60 \%$ dos pacientes, sendo esta enfermidade a principal causa de maus resultados no tratamento. O alcoolismo é encontrado em $25 \%$ a $50 \%$ dos casos. A associação com HIV deve ser pesquisada, pois houve índices de pior prognóstico nesta afecção. A desnutrição gerou impactos negativos na sobrevida dos pacientes. Outras doenças aparecem como fatores de risco, como hipertensão arterial, tabagismo, obesidade, linfomas ${ }^{4,5}$.

Vários microrganismos aparecem como patógenos nas culturas dos pacientes com essa enfermidade. Bactérias que habitualmente não são patogênicas, em condições favoráveis podem provocar a doença. Os microrganismos mais frequentemente isolados entre os Gram negativos aeróbios são Escherichia coli, Klebsiella pneumoniae, Pseudomonas aeruginosa e Proteus mirabilis. Entre os aeróbios Gram positivos destacam-se o Staphylococcus aureus, o Staphylococcus epidermidis, Streptococcus viridans e o Streptococcus fecalis. Os anaeróbios estão representados pelo Bacteróides fragilis, Bacteróides melaninogenicus, cocos Gram positivos e Clostridium species (não perfringens) ${ }^{5}$.

$\mathrm{O}$ quadro clínico pode se manifestar com dor intensa, eritema e edema, até bolhas e escaras, em bolsa escrotal e períneo, podendo se estender para parede abdominal e raiz da coxa, associada ou não a febre e calafrios. Alguns casos podem gerar sepse logo de início. Outras manifestações locais comuns podem aparecer como: cianose, crepitação e secreção com forte e repulsivo odor fétido. A suspeita diagnóstica deve ser levantada quando esses sinais e sintomas evoluem com piora progressiva em poucos dias. A exclusão de outras doenças também aumenta a suspeita clinica. Entre os diagnósticos diferenciais estão: celulite, hérnia estrangulada, abscesso de escroto, fasciite necrotizante estreptocócica ou estafilocócica, herpes simples, pioderma gangrenoso, necrose pelo warfarin, entre outros ${ }^{5}$.

Em relação aos achados laboratoriais, verificou-se alterações do hematócrito, ureia, cálcio, albumina, fosfatase alcalina e colesterol ${ }^{4}$, embora não tenham importância prática.
Diagnóstico e intervenção precoce, com antibioticoterapia de largo espectro e drenagem ampla, permitiram melhores desfechos nestes doentes. Os pacientes submetidos a desbridamento cirúrgico tardiamente possuem mortalidade próxima de $100 \%{ }^{6}$.

A oxigenoterapia hiperbárica e os curativos a vácuo tem sua eficácia por removerem exsudatos, promoverem a cobertura da ferida por tecido de granulação estimulando a angiogênese e reduzirem a contaminação bacteriana ${ }^{6}$ No entanto, são tratamentos adjuvantes dispensáveis.

A mortalidade permanece elevada quando o diagnóstico é tardio e o procedimento cirúrgico é retardado, alcançando em alguns estudos $30 \%$ a $50 \%$, aumentando para até $80 \%$ em diabéticos e idosos ${ }^{7}$.

\section{OBJETIVO}

Relatar um caso de Síndrome de Fournier em um paciente de 52 anos, discutir a melhor abordagem cirúrgica e seus impactos no sucesso terapêutico nesta enfermidade.

\section{RELATO DO CASO}

M.D.F.G, 52 anos, pardo, sexo masculino, portador de fístula perianal crônica há 30 anos, sem diagnóstico de base conclusivo. Procurou o Pronto Socorro no dia 08/11/15 com quadro de dor perianal há três dias associado à tumoração local. Negava doenças de base ou uso de medicação contínua. Sem historia de cirurgias prévias.

Ao exame, presença de múltiplas cicatrizes de fístulas e abscesso em região perianal. No toque retal foi palpável tumoração dolorosa em parede lateral direita e posterior. No momento da internação, o paciente se apresentava lúcido, orientado, afebril, eupneico e hemodinamicamente estável.

Foi solicitado retossigmoidoscopia, P-ANCA, ASCA, HIV, sorologias para Leishmaniose e exames laboratoriais de rotina hospitalar.

Realizado drenagem do abscesso com saída de secreção purulenta em grande quantidade e iniciado antibioticoterapia com Ciprofloxacina e Metronidazol

No dia 12/11/15 notou-se edema testicular, hiperemia e calor local associado a transiluminação escrotal positiva para líquido. No dia 13/11/15 foi realizado abordagem cirúrgica da lesão com incisão da bolsa escrotal. Foi observado no ato cirúrgico secreção purulenta em grande quantidade e tecido necrosado na lesão, como extensão a partir do abscesso perianal, além do testículo direito com aspecto necrosado. Realizado orquiectomia direita e drenagem ampla, comunicando-se a região periretal com a região escrotal. Realizado cultura de material colhido em procedimento cirúrgico e iniciado Ampicilina Sulbactam e Clindamicina.

Sorologias para Leishmaniose, P-ANCA, ASCA, HIV todos negativos. Cultura de Secreção mostrou 
crescimento de Pseudomonas aeuriginosa. Iniciado Cefepime no dia 20/11/15 após resultado de cultura com antibiograma.

Paciente evoluiu com melhora do aspecto das lesões após a drenagem e ressecção de tecido necrosado. No dia 21/11/15 foi submetido à sutura de pele e aproximação da ferida (fechamento primário retardado), interrompendo a cicatrização por segunda intenção.

Paciente evoluiu com melhora do quadro clínico após troca de antibiótico e fechamento da ferida.

No dia 04/12/15 identificou-se endurecimento perianal e secreção fecalóide na ferida, sendo cogitada realização de colostomia.

A ferida operatória apresentou melhora do aspecto após medidas conservadoras de controle de infecção. Não houve necessidade de colostomia ou outras intervenções cirúrgicas. Paciente recebeu alta hospitalar no dia 08/12/15 em bom estado geral e sem outras intercorrências.

O tempo entre a admissão e o final dos procedimentos reconstrutivos foi de 30 dias. As imagens (Figura 1) mostram a evolução do quadro, antes e após a intervenção cirúrgica.

A técnica de fechamento primário retardado, associado a antibioticoterapia de amplo espectro, foi eficiente: obteve bom aspecto estético e abreviou o tratamento.

Ocorreram algumas complicações como pequena quantidade de secreção drenando da ferida e endurecimento perineal, porém não foram suficientes para comprometerem o resultado final.

O paciente recebeu alta hospitalar ciente da gravidade do quadro e satisfeito com o resultado do tratamento.
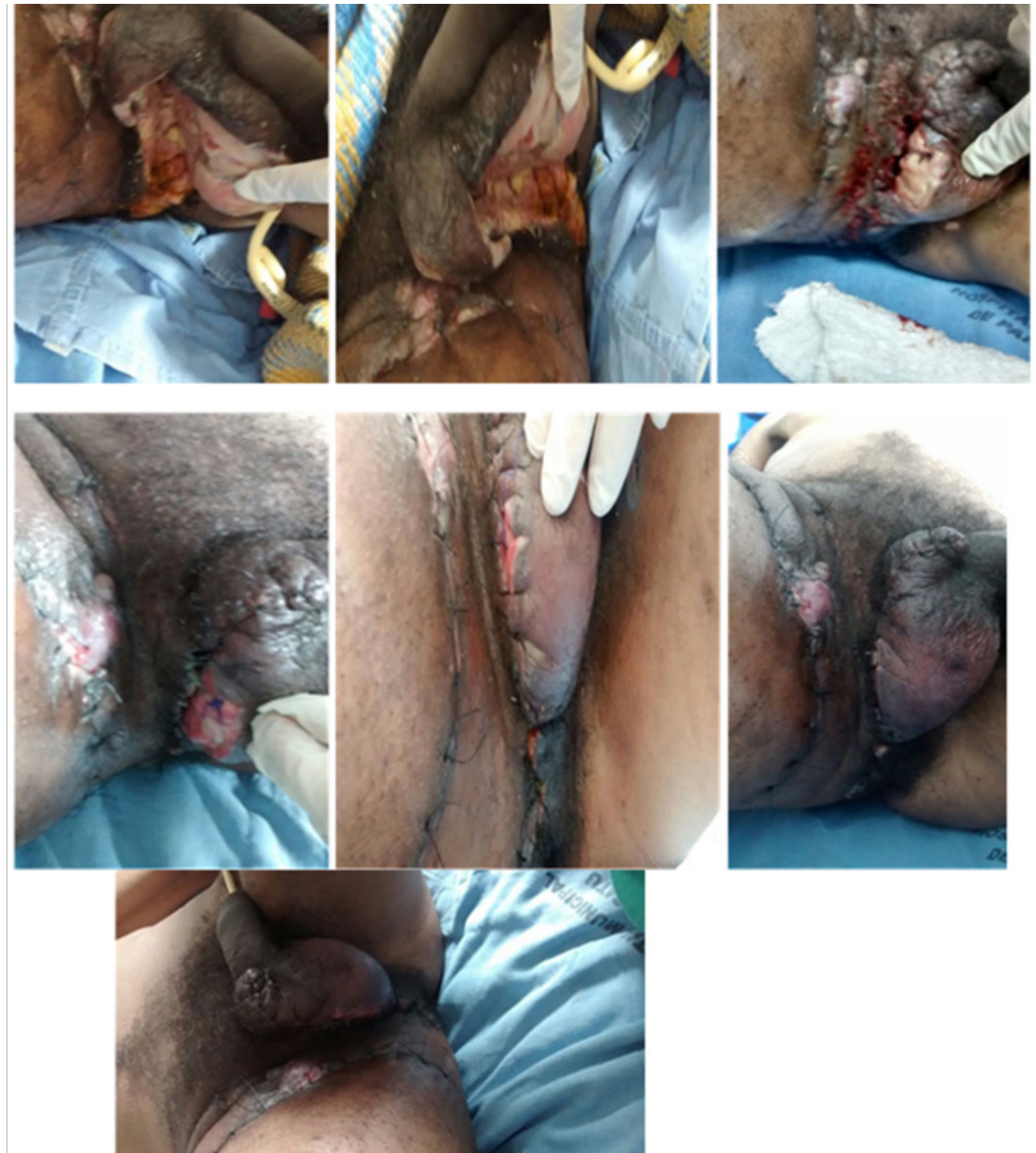

Figura 1. Aspectos evolutivos do tratamento cirúrgico da síndrome de Fournier baseado em fechamento precoce por suturas primárias 


\section{DISCUSSÃO}

A síndrome de Fournier está associada a vários fatores causais e comorbidades, sendo descritos como fatores de risco para a Síndrome de Fournier o abscesso anorretal, alcoolismo, diabetes mellitus, cirrose, obesidade, desnutrição, doença vascular periférica, cirurgias orificiais, vasectomia, trauma perineal, neoplasia colorretal avançada, estenose uretral, neoplasias hematológicas, radioterapia, HIV, apendicite, diverticulite aguda, hérnia estrangulada e doença inflamatória intestinal ${ }^{8}$.

No paciente relatado, foram pesquisado diversos fatores de risco, tendo-se observado a presença de cicatrizes de fístulas anorretais anteriores e uma tumoração ao toque retal sugestiva de abscesso anorretal.

A apresentação clínica do paciente com síndrome de Fournier pode ser variável; porém o quadro mais comumente encontrado é hiperemia, dor, crepitação, edema de região perianal, drenagem de secreção serosa e febre, podendo evoluir para choque séptico?.

O paciente do caso evoluiu com melhora após passar por diversas intervenções terapêuticas, sendo observado que, como em outros trabalhos já publicados sobre o assunto, a união de abordagens cirúrgicas e farmacológicas é imprescindível para o sucesso do tratamento ${ }^{4,6,10,11}$.

Com relação ao tratamento clínico, diversos esquemas antibióticos são utilizados, mas não parecem interferir no êxito, desde que obedeçam ao espectro bacteriológico da doença. Como citado no manual de Levin et al. ${ }^{12}$, e utilizado no paciente, o emprego de imediato da Clindamicina é importante para controle e eliminação da flora bacteriana mista da Síndrome de Fournier, mesmo havendo troca do esquema orientado por cultura da secreção. Na questão técnica cirúrgica, drenagem ampla precoce, dissecando-se digitalmente sobre a fáscia pélvica, expondo-se a fáscia necrosada, transformando o ambiente anaeróbio em oxigenado e, ao mesmo tempo, preservando o máximo de pele possível (para futuro fechamento da ferida), parece fundamental para abortar a evolução da infecção e promover a reação inflamatório/cicatricial. A observação cuidadosa é importante para verificar-se a necessidade de novos desbridamentos que, na maioria

\section{REFERÊNCIAS}

1. Benizri E, Fabiani P, Migliori G, Chevallier D, Pevrottes A, Raucoules M, Amiel J, Mouiel J, Toubol J. Gangrene of the perineum. Urology. 1996;47:935-9. doi: http://dx.doi. org/10.1016/S0090-4295(96)00058-1.

2. Leporaes RI, Pereira JN, Botelho FA, Barbosa PS, Barros MGCRM. Relato de caso: síndrome de Fournier em mulher jovem. 2015 [citado 8 nov. 2015]. Disponível em: http://www. clinicamedica2015.com.br/upload/trabalhos/599KmDDWBZ pfMYRsGOpBhDfVRSC2.pdf. das vezes, ficarão restritos a pele, inicialmente de aspecto duvidoso e que evoluiu com necrose $\mathrm{e}^{10,13}$.

A realização de colostomia apresenta controvérsias, sendo indicada quando o paciente não consegue higienizar a região adequadamente, ocorrendo contaminação grosseira da ferida cirúrgica durante o tratamento. No entanto, na maioria dos casos, não mostrou benefício e não está isenta de complicações. Neste paciente também não foi realizada colostomia e o tratamento foi realizado com sucesso, ${ }^{1,3,14}$. Há ainda relatos na literatura da realização de cistostomia em casos de estenose uretral ou fonte genitourinária da infecção, procedimento este que não houve necessidade em nosso caso ${ }^{11}$.

Neste paciente foi optado, ainda, por fechamento primário retardado ao invés de se permitir a cicatrização por segunda intenção. Poderia ter sido realizado ainda autoenxertia local, procedimento este que não foi feito ${ }^{6}$. Não há relatos na literatura quanto ao fechamento precoce da lesão uma vez que, para que se possa suturar a ferida, a infecção deve estar controlada, o que demora alguns dias.

A oxigenoterapia hiperbárica e o curativo a vácuo têm sua eficácia no tratamento da Síndrome de Fournier demonstradas em vários estudos, uma vez que removem exsudatos, promovem a granulação da ferida estimulando a angiogênese e reduzem a contaminação bacteriana. Essas modalidades de tratamento são adjuvantes e não substituem as demais citadas acima ${ }^{6}$.

\section{CONCLUSÃo}

Por sua gravidade, a Síndrome de Fournier carece de rápida intervenção, drenagem precoce ampla, antibioticoterapia de largo espectro e cuidados gerais conservadores da ferida operatória. Embora a abordagem cirúrgica ainda não seja consensual, a conduta de fechamento primário retardado da ferida contribuiu para o desfecho satisfatório da doença. Técnicas avançadas na abordagem terapêutica (oxigênioterapia hiperbarica $\mathrm{p}$. ex.) vêm sendo empregadas em alguns serviços, porém as mesmas ainda não são disponíveis com facilidade por seu alto custo, e não há evidências de superioridade ao tratamento realizado até o momento, segundo a Literatura.

3. Hollabough Junior RS, Dmochowski RR, Hickerson WL, Cox CE. Fourniers gangrene: therapeutic impact of hyperbaric oxigen. Plast Reconst Surg. 1998;101(1):94-100.

4. Candelária PAP, Klug WA, Capelhuchnik P, Fang CB. Síndrome de Fournier: análise dos fatores de mortalidade. Rev Bras Coloproctol. 2009;29(2):197-202. doi: 10.1590/ S0101-98802009000200006.

5. Cardoso JB, Féres O. Gangrena de Fournier. Medicina (Ribeirão Preto). 2007;40(4):493-9. doi: http://dx.doi. 
org/10.11606/issn.2176-7262.v40i4p493-499.

6. Dornelas MT, Correia MPD, Barra FML, Corrêa LD, Silva EC, Dornelas GV, et al. Síndrome de Fournier: 10 anos de avaliação. Rev Bras Cir Plast. 2012;27(4):600-4. doi: http:// dx.doi.org/10.1590/S1983-51752012000400022.

7. Hoffmann AL, Iglesias LF, Rothbarth WW. Síndrome de Fournier: relato de caso. Arq Catarinenses Med. 2009;38(1):104-5. Disponível em: http://www.acm.org.br/ revista/pdf/artigos/666.pdf.

8. Batista RR, Filho PRR, Castro MFMF, Albuquerque IC, Formiga GJS. Síndrome de Fournier secundária adenocarcinoma de próstata avançado: relato de caso. Rev Bras Coloproctol. 2010;30(2):228-31. doi: 10.1590/S010198802010000200016.

9. Eltorai IM, Hart GB, Strauss MB, Montroy R, Juler GL. The role of hyperbaric oxygen in the management of Fournier's gangrene. Int Surg. 1986;71(1):53-8.

Recebido em: 18.06.16

Aceito em: 09.03.17
10. Steinman R, Utiyama EM, Maximiniano LF, Bevilacqua RG, Birolini D. Síndrome de Fournier: avaliação e tratamento inicial. Rev Assoc Med Bras. 1992;38:209-13.

11. Mehl AA, Filho DCN, Mantovani LM, Grippa MM, Berger R, Krauss D, Ribas D. Manejo da gangrena de Fournier: experiência de um hospital universitário de Curitiba. Rev Col Bras Cir. 2010;37(6):435-41. doi: http://dx.doi.org/10.1590/ S0100-69912010000600010.

12. Levin ASS, Dias MBS, Oliveira MS, Lobo, RD. Guia de utilização de anti-infecciosos e recomendações para a prevenção de infecções hospitalares. 5a ed. São Paulo: Hospital das Clínicas; 2012-2014.

13. ThambiDorai CR, Kandasami P. Fourniers gangrene: its aetilogy and management. Aust N Z J Surg. 1991;61:371-2.

14. Capelhuchnik P, Chia-Bin F, Klug WA. Enfermedad de Fournier: factores que influyen sobre la mortalidad. Coloproctology. 1994;10:180-5. doi: http://dx.doi. org/10.1016/j.rchic.2015.11.003. 